\title{
Platelet Activation Problem
}

National Cancer Institute

\section{Source}

National Cancer Institute. Platelet Activation Problem. NCI Thesaurus. Code C92095.

The device affects the body's ability to activate platelet formation. 